\title{
Effect of Chromolaena Odorata on Hepatotoxicology and Histopathology in the Liver Induced by Salmonella Typhi in Wistar Rats
}

Isirima Joshua Charles, M.Sc

Department of Biomedical Technology, School of Science Laboratory Technology, University of Port Harcourt, Nigeria

Siminialayi Iyeopu Minakiri, Prof.

Department of Pharmacology, Faculty of Basic Medical Sciences, College of Health Sciences, University of Port Harcourt, Nigeria

Doi: 10.19044/esj.2018.v14n12p421 URL:http://dx.doi.org/10.19044/esj.2018.v14n12p421

\begin{abstract}
Typhoid fever, also known as enteric fever, is caused by the human restricted bacterial pathogen known as Salmonella enterica serovars typhi, which is always associated with liver pathology. This study attempts to investigate the Hepatotoxicological and Histopathological changes of the liver associated with Salmonella typhi infection in Wistar rats and to examine the potential of methanol leaf extract of Chromolaena odorata (MLECO) to reverse these adverse changes in comparison to ciprofloxacin treatment. The animals were divided into six groups: group 1 was normal control, group 2 was infected with Salmonella typhi without treatment (negative control), group 3, 4 and 5 were Salmonella typhi infected and treated with $100 \mathrm{mg} / \mathrm{kg}$, $200 \mathrm{mg} / \mathrm{kg}$ and $400 \mathrm{mg} / \mathrm{kg}$ of the extract respectively, and group 6 was infected and treated with $500 \mathrm{mg} / 70 \mathrm{~kg}$ of ciprofloxacin. The animals were inoculated with a single contagious dose of Salmonella typhi bacteria and were subsequently treated with the graded doses of the extract and $500 \mathrm{mg} / 70 \mathrm{~kg}$ dose of ciprofloxacin for a period of fifteen days, after the animals were confirmed infected. The rats were humanely sacrificed using diethyl ether anesthesia and blood samples taken for liver function investigation and liver harvested and processed for histological examination. MLECO reversed the adverse hepatotoxicological and pathological changes in the liver induced by S. tyhi infection in a dose-dependent manner. This was done with the $200 \mathrm{mg}$ and $400 \mathrm{mg}$ doses being more effective at reversing liver changes than ciprofloxacin.
\end{abstract}

Keywords: Chromolaena odorata, Hepatotoxicity, Liver Histopathology, Salmonella typhi, Wistar Rats 


\section{Introduction}

Infection with typhoid fever is always associated with liver pathology, although reports by Abro et al. (2009) revealed that intensive hepatic damage leading to acute viral hepatitis is not common. Hepatic damage in typhoid fever, according to Sallie et al. (1991), has numerous fundamental mechanisms including local or systemic adverse effects of a particular endotoxin, non-specific inflammatory reactions in response to intestinal perforations, and cytotoxins generated and released by Salmonella typhi that have infected Kupffer cells. The frequency of liver enzymes elevation in typhoid fever has been reported by Mirsadraee, et al. (2007) and Morgenstern \& Hayes (1991) as 22\%, 26\% and 52\% in various case series. On the other hand, Abro et al. (2009) in his study still reported higher incidence of elevated alanine transaminases levels of $73.3 \%$ in typhoid patients. Furthermore, Momoh, et al. (2013) reported a decrease in total bilirubin (TB), and an increase in serum total protein (STP), aspartate aminotransferase (AST), alanine aminotransferase (ALT), and alkaline phosphatase (ALP) in salmonella typhi infection. Adeyi et al. (2013) also reported an increase in ALT, AST, ALP, Gamma-glutamyltransferase (GGT), and TB in Salmonela typhi infection. Chromolaena odorata, on the contrary, has been reported to cause effects that were seemingly opposite to those of Salmonella typhi on hepatic parameters. For instance, Ogbonnia et al. (2010) reported a decrease in the ALT and total plasma protein, while Musa (2012) reported reduction in ALP. Nwachukwu et al. (2015) and Asomugha et al. (2015) reported a decrease in total protein and albumin on administration of Chromolaena odorarta. It has been reported that sections of the liver from animals inoculated with salmonella without treatment revealed a mild hepatitis, normal lobular outlines with normal hepatocytes arranged in interconnecting chords as well as mild aggregations of mononuclear leukocytes in the periportal areas (Damilola et al., 2015). Additionally, Haque et al. (2011) have reported numerous lesions of nodular micro-abscess or granulomatous lesions which were made-up of degenerated hepatocytes with different degrees of central necrosis bound by sheets of neutrophils and macrophages with observable necrosis in Salmonella typhi infected animals. Preeti et al. (2016) also reported major infiltration of the liver cells by lymphocytes with the sinusoids seen to be dilated with Kupffer cells and lymphocytes infiltrating these dilated sinusoids. However, other observations made included fairly heavy lobular hepatitis, micro-vesicular fatty changes, hepatocyte degeneration and destruction, acute liver necrosis and chronic portal triaditis as well as localized clusters of lymphocytes resulting in the formation of typical "typhoidal nodules" (Preeti, et al., 2016). 


\section{Methods}

\section{Collection of Samples}

Leaves of Chromolaena odorata were fetched from Omuoko-Aluu community of Rivers State, Nigeria and were cleaned from soil and dust by washing with tap water. The leaves were identified at the Department of Plant Science and Biotechnology, University of Port Harcourt.

\section{Plant Extraction}

After collection, the leaves of the plant were shade-dried at room temperature $\left(32-35^{\circ} \mathrm{C}\right)$ to a constant weight over a period of seven (7) days. The method employed a little modification of the cold maceration extraction method described by Hanan et al. (2013). 50g of powdered leaves of Chromolaena odorata was dissolved in $1000 \mathrm{ml}$ of seventy percent methanol in a 2 litre conical flask and was shaken vigorously at 1 hour intervals. This was done for a period of 12 hours and was left to stand over-night at room temperature for effective extraction. Afterwards, the mixture was filtered using a 0.45 millipore filter paper. The clear solution obtained was then concentrated with a rotary evaporator at $40^{\circ} \mathrm{C}$ and $200 \mathrm{rpm}$ and subsequently, on a steam bath at $40^{\circ} \mathrm{C}$. The semi-solid extract obtained was stored in sterile pre-weighed screw capped bottles and was labeled accordingly. The extracts were stored in desiccators at room temperature until when needed.

\section{Isolation and Culturing of the Organism}

All media used in this study were prepared following the manufacturer's instruction. Salmonella typhi was isolated from typhoid patients at "University of Port Harcourt Teaching Hospital'" Rivers State, Nigeria. Bile salt broth (broth culture) (Watson, 1954) and streptokinase broth (clot culture; Watson, 1978) were used for enrichment. The enriched samples showing visible turbidity were streaked on Mac-Conkey agar media. The isolates producing characteristic colonies were identified by conventional biochemical tests.

\section{Experimental Design}

Eighty five (85) animals were divided into 6 groups of 1-6. Group 1 (normal) had five (5) animals, group 2 (negative control) had twenty (20) animals, while groups 3-6 each had fifteen (15) animals. Group 1 animals were not treated throughout the experiment but were given free access to normal animal feed and water ad libitum. Group 2 animals were Salmonella typhiinfected but were not treated after disease induction. Group 3 animals were Salmonella typhi-infected and were treated with $100 \mathrm{mg} / \mathrm{kg}$ (low dose) of MLECO. Group 4 rats were Salmonella typhi-infected and were treated with $200 \mathrm{mg} / \mathrm{kg}$ (medium dose) of methanol leaf extract of Chromolena odorata. 
Group 5 rats Salmonella typhi-infected and were treated with $400 \mathrm{mg} / \mathrm{kg}$ (high dose) of methanol leaf extract of Chromolena odorata. Group 6 rats were Salmonella typhi-infected and were treated with $500 \mathrm{mg} / 70 \mathrm{~kg}$ of a standard antibiotic drug (Ciprofloxacin). On day 0, the animals were confirmed infected through observation of anorexia, weakness, and diarrhea from the animals as well as isolation of the organism from the animals' stools. On day 6 and on days 11 and 16, 5 animals from each group were humanely sacrificed using diethyl ether as anesthesia and blood was collected and the liver removed aseptically for assessment of liver function parameters and histopathological examination, respectively.

\section{Challenging Apparently Healthy Animals with Salmonella Typhi}

Eighty (80) animals (groups 2-6) were orogastrically challenged with an infective dose $\left(2.0 \times 10^{8} \mathrm{cfu} / \mathrm{ml}\right)$ of Salmonella typhi. After infection had set in (day 0), five animals were sacrificed and blood samples and liver tissues were collected for preliminary screening, while the other 75 animals were treated with the methanol leaf extract of Chromolaena odorata according to the different doses specified for each sub-group and the standard antibiotic (Ciprofloxacin), once daily, for seventeen days.

\section{Preparation of the Extract Concentrations and Antibiotic}

Stock solutions for the extract were prepared by dissolving $500 \mathrm{mg}$ in $1 \mathrm{ml}$ of dimethylsulfoxide (DMSO). An antibiotic control was made by dissolving 500mg of ciprofloxacin in sterile distilled water. DMSO was also used as vehicle control in the study.

\section{Blood Collection and Dissection}

Blood was collected from each animal by cardiac puncture method after the animals were anaesthetized with diethyl ether in a desiccator. The blood was immediately transferred into appropriately labelled sample bottles containing anticoagulant. The liver was removed aseptically and was weighed and a portion was kept for histological analysis.

\section{Liver Function Test Analysis}

Aspartate aminotransferase (AST) and alanine aminotransferase (ALT) determinations were carried out using Randox automated method and the methods of Reitman and Frankel (1957) and Schmidt and Schmidt (1963). On the other hand, alkaline phosphatase (ALP) determination was carried out using Randox automated method and the methods of Klein and Babson (1960) and Babson, et al. (1966). In a similar manner, total protein (TP) determination was carried out using Randox automated method and the method of Tietz (1995), while albumin (ALB) and bilirubin (BIL) determinations were carried 
out using Randox automated method and the methods of Grant (1987) and Doumas, et al. (1971).

\section{Histopathology Studies}

The animals were anaesthetized with chloroform, dissected aseptically to remove the spleen which was then transferred into $10 \%$ chloroform, and it was later trimmed down to a size of $2 \mathrm{~mm}$ to $4 \mathrm{~mm}$ thickness. This was done to allow the fixative to readily penetrate the tissue. The tissues were exposed to different stages of processing by standard methods as described by Baker (1945), including, fixation, dehydration, clearing, impregnation, embedding, sectioning and staining with hematoxylin and eosin (H\&E), and finally mounting.

\section{Statistical Analysis}

The results are presented as Mean \pm Standard error of mean. Differences between means were assessed using Analysis of variance (ANOVA) and post test using LSD multiple comparison test (Mead \& Curnow, 1982).

\section{Results}

Exposure of Wistar rats to a single infective dose of Salmonella typhi caused a statistically significant increase $(\mathrm{p}<0.05)$ in the mean aspartate aminotransferase (AST), alanine aminotransferase (ALT), alkaline phosphatase (ALP), total bilirubin (TB), albumin and total protein (TP) levels except for conjugated bilirubin (CB) where the increase was not significant. Conversely, administration of the standard drug and the extract reversed the increases observed, giving rise to a gradual decrease in all these parameters. ANOVA comparison showed statistically significant difference $(p<0.05)$ between negative control and normal groups throughout the study, in all the parameters except CB. There was a similar statistically significant difference $(\mathrm{p}<0.05)$ between the negative control and other treatment groups on days 11 and 16 in ALT, ALP, TB, albumin, and TP as shown in tables 2, 3, 4, 6 and 7 respectively. Also, there was a statistically significant difference $(p<0.05)$ between the negative control and other treatment groups on day 16 in AST and $\mathrm{CB}$ as shown in tables 1 and 5.

Histological examination of liver tissues from normal Albino rats showed normal architecture of the hepatocytes, while severe necrosis was observed from Salmonella typhi infected animals. For animals treated with $100 \mathrm{mg} / \mathrm{kg}$ of Chromolaena odorata leaf extract, observation of the liver architecture revealed destroyed hepatic tissues after 5 days of treatment, slight tissue disruption of hepatocytes after 10 days of treatment, and normal hepatic tissue after 15 days of treatment. This implies a progressive positive effect of 
the extract on the liver cells at this dose in typhoid infection. For animals treated with $200 \mathrm{mg} / \mathrm{kg}$ of Chromolaena odorata leaf extract, observation of the liver architecture revealed congestion of the sinusoids and fuzzy appearance of the hepatic plates after 5 days of treatment with the extract, clearly defined hepatic plates and sinusoids after 10 days of treatment and normal tissue architecture revealing a central vein and radially placed hepatic plates, and clearly demarcated by sinusoids after 15 days of treatment. For animals treated with $400 \mathrm{mg} / \mathrm{kg}$ of Chromolaena odorata leaf extract, observation of the liver architecture revealed destroyed hepatic tissue architecture with highly dilated sinusoids after 5 days of treatment, still fairly dilated sinusoids after 10 days of treatment, and normal tissues after 15 days of treatment. For animals treated with $500 \mathrm{mg} / 70 \mathrm{~kg}$ of ciprofloxacin observation of the liver, architecture revealed no tissue disruption, portal triad with well dilated sinusoids without any inflammatory cells after 5 days of treatment, while day 10 of treatment revealed sinusoids with well defined hepatic plates without any inflammatory cells. After 15 day of treatment with $500 \mathrm{mg} / 70 \mathrm{~kg}$ of ciprofloxacin, the liver tissue showed the interlobular region with congested interlobar portal vein. The hepatocytes had normal architecture.

Table 1. Effect of methanol leaf extract of Chromolaena odorata on Aspartate aminotransferase [AST (U/L)] in Salmonella typhi infected Wistar Rats

\begin{tabular}{lllll}
\hline Group & Day 0 & Day 6 & Day 11 & Day 16 \\
\hline Control & $75.00 \pm 3.06$ & $75.00 \pm 3.06$ & $75.00 \pm 3.06$ & $75.00 \pm 3.06$ \\
Neg. Control & $134.00 \pm 18.61 * *$ & $136.67 \pm 15.96 * *$ & $142.00 \pm 18.68 * *$ & $150.67 \pm 10.17 * *$ \\
Low Dose & $134.00 \pm 18.61 *$ & $130.00 \pm 10.97 *$ & $* 114.33 \pm 7.22$ & $104.33 \pm 15.68 * * *$ \\
Medium Dose & $134.00 \pm 18.61 *$ & $118.00 \pm 3.61 *$ & $* 112.33 \pm 6.23$ & $101.67 \pm 14.62 * * *$ \\
High Dose & $134.00 \pm 18.61 *$ & $110.67 \pm 5.36 *$ & $97.67 \pm 13.87 * * *$ & $89.33 \pm 8.1 * * *$ \\
Ciprofloxacin & $134.00 \pm 18.61 *$ & $117.00 \pm 3.06 *$ & $* 108.67 \pm 6.36 * * *$ & $97.00 \pm 13.86 * * *$ \\
\hline
\end{tabular}

$\begin{array}{lll}* & = & \text { Significant difference between normal and test groups } \\ * * & = & \text { Significant difference between normal and negative control } \\ * * * & = & \text { Significant difference between and negative control and test groups }\end{array}$

- Normal (Animals not exposed to any form of treatment but were fed ad libitum)

- Negative Control (Animals inoculated with Salmonella typhi without treatment)

- Low Dose $(100 \mathrm{mg} / \mathrm{kg}$ of extract)

- Medium Dose $(200 \mathrm{mg} / \mathrm{kg}$ of extract)

- High Dose $(400 \mathrm{mg} / \mathrm{kg}$ of extract)

- Ciprofloxacin $(500 \mathrm{mg} / 70 \mathrm{~kg})$ 
Table 2. Effect of methanol leaf extract of Chromolaena odorata on Alanine aminotransferase [ALT (U/L)] in Salmonella typhi infected Wistar Rats

\begin{tabular}{lllll}
\hline Group & Day 0 & Day 6 & Day 11 & Day 16 \\
\hline Control & $26.17 \pm 2.96$ & $26.17 \pm 2.96$ & $26.17 \pm 2.96$ & $26.17 \pm 2.96$ \\
Neg. Control & $47.77 \pm 4.25 * *$ & $49.20 \pm 2.94 * *$ & $49.83 \pm 3.01 * *$ & $51.87 \pm 4.72 * *$ \\
Low Dose & $47.77 \pm 4.25 *$ & $* 45.47 \pm 2.88$ & $* 42.57 \pm 2.43$ & $32.20 \pm 3.66 * * *$ \\
Medium Dose & $47.77 \pm 4.25 *$ & $* 42.70 \pm 1.86$ & $31.87 \pm 2.96 * * *$ & $27.97 \pm 1.13 * * *$ \\
High Dose & $47.77 \pm 4.25 *$ & $33.60 \pm 3.26 * * *$ & $25.47 \pm 1.39 * * *$ & $21.80 \pm 2.68 * * *$ \\
Ciprofloxacin & $47.77 \pm 4.25 *$ & $* 41.70 \pm 0.87$ & $30.53 \pm 1.82 * * *$ & $25.70 \pm 3.08 * * *$ \\
\hline
\end{tabular}

Table 3. Effect of methanol leaf extract of Chromolaena odorata on Alkaline Phosphatase [ALP (U/L)] in Salmonella typhi infected Wistar Rats

\begin{tabular}{lllll}
\hline Group & Day 0 & Day 6 & Day 11 & Day 16 \\
\hline Control & $100.90 \pm 18.60$ & $100.90 \pm 18.60$ & $100.90 \pm 18.60$ & $100.90 \pm 18.60$ \\
Neg. Control & $173.40 \pm 9.77 * *$ & $175.73 \pm 10.16^{* *}$ & $178.00 \pm 11.21 * *$ & $181.33 \pm 7.89 * *$ \\
Low Dose & $173.40 \pm 9.77 *$ & $156.73 \pm 17.12^{*}$ & $140.07 \pm 8.86^{*}$ & $100.63 \pm 6.19 * * *$ \\
Medium Dose & $173.40 \pm 9.77 *$ & $146.73 \pm 6.62 *$ & $107.30 \pm 8.96 * * *$ & $91.80 \pm 3.53 * * *$ \\
High Dose & $173.40 \pm 9.77 *$ & $127.30 \pm 16.55^{* * * *}$ & $102.27 \pm 13.66 * * *$ & $76.80 \pm 7.59 * * *$ \\
Ciprofloxacin & $173.40 \pm 9.77 *$ & $143.73 \pm 7.27 *$ & $104.63 \pm 9.23 * * *$ & $88.47 \pm 6.57 * * *$ \\
\hline
\end{tabular}

Table 4. Effect of methanol leaf extract of Chromolaena odorata on Total Bilirubin [TB $(\mu \mathrm{mol} / \mathrm{l})]$ in Salmonella typhi infected Wistar Rats

\begin{tabular}{lllll}
\hline Group & Day 0 & Day 6 & Day 11 & Day 16 \\
\hline Normal & $0.10 \pm 0.02$ & $0.10 \pm 0.02$ & $0.10 \pm 0.01$ & $0.11 \pm 0.02$ \\
N. Control & $0.27 \pm 0.03 * *$ & $0.22 \pm 0.01 * *$ & $0.23 \pm 0.01 * *$ & $0.20 \pm 0.01 * *$ \\
Low Dose & $0.27 \pm 0.03 *$ & $0.21 \pm 0.04 *$ & $0.18 \pm 0.02$ & $0.14 \pm 0.01 * * *$ \\
Medium Dose & $0.27 \pm 0.03 *$ & $0.21 \pm 0.02 *$ & $0.16 \pm 0.02 * * *$ & $0.11 \pm 0.01 * * *$ \\
High Dose & $0.27 \pm 0.03 *$ & $0.19 \pm 0.02 *$ & $0.13 \pm 0.02 * * *$ & $0.08 \pm 0.02 * * *$ \\
Ciprofloxacin & $0.27 \pm 0.03 *$ & $0.21 \pm 0.01 *$ & $0.18 \pm 0.01$ & $0.10 \pm 0.01 * * *$ \\
\hline
\end{tabular}

Table 5. Effect of methanol leaf extract of Chromolaena odorata on Conjugate Bilirubin [CB ( $\mu \mathrm{mol} / \mathrm{l})]$ in Salmonella typhi infected Wistar Rats

\begin{tabular}{lllll}
\hline Group & Day 0 & Day 6 & Day 11 & Day 16 \\
\hline Control & $0.10 \pm 0.04$ & $0.10 \pm 0.04$ & $0.10 \pm 0.04$ & $0.10 \pm 0.04$ \\
Neg. Control & $0.30 \pm 0.14$ & $.31 \pm 0.15$ & $.34 \pm 0.14$ & $.36 \pm 0.12 * *$
\end{tabular}




\begin{tabular}{lllll} 
Low Dose & $0.30 \pm 0.14$ & $.26 \pm 0.11$ & $.22 \pm 0.13$ & $.18 \pm 0.10$ \\
Medium Dose & $0.30 \pm 0.14$ & $.22 \pm 0.10$ & $.20 \pm 0.10$ & $.11 \pm 0.05 * * *$ \\
High Dose & $0.30 \pm 0.14$ & $.21 \pm 0.10$ & $.13 \pm 0.04$ & $.08 \pm 0.05 * * *$ \\
Ciprofloxacin & $0.30 \pm 0.14$ & $.22 \pm 0.10$ & $.17 \pm 0.07$ & $.10 \pm 0.04 * * *$ \\
\hline
\end{tabular}

Table 6. Effect of methanol leaf extract of Chromolaena odorata on Albumin (g/dl) in Salmonella typhi infected Wistar Rats

\begin{tabular}{lllll}
\hline Group & Day 0 & Day 6 & Day 11 & Day 16 \\
\hline Control & $4.43 \pm 0.56$ & $4.43 \pm 0.56$ & $4.43 \pm 0.56$ & $4.43 \pm 0.56$ \\
Neg. Control & $6.27 \pm 0.23 * *$ & $6.13 \pm 0.19 * *$ & $6.30 \pm 0.23 * *$ & $5.63 \pm 0.12 * *$ \\
Low Dose & $6.27 \pm 0.23 *$ & $5.73 \pm 0.09 *$ & $5.10 \pm 0.06 * * *$ & $4.53 \pm 0.29 * * *$ \\
Medium Dose & $6.27 \pm 0.23^{*}$ & $5.47 \pm 0.23 *$ & $4.80 \pm 0.46 * * *$ & $4.13 \pm 0.09 * * *$ \\
High Dose & $6.27 \pm 0.23^{*}$ & $5.10 \pm 0.17 * * *$ & $4.57 \pm 0.09 * * *$ & $3.73 \pm 0.15^{* * *}$ \\
Ciprofloxacin & $6.27 \pm 0.23^{*}$ & $5.40 \pm 0.23 *$ & $5.10 \pm 0.06 * * *$ & $3.93 \pm 0.23 * * *$ \\
\hline
\end{tabular}

Table 7. Effect of methanol leaf extract of Chromolaena odorata on Total Protein [TP (g/dl)] in animals inoculated with Salmonella typhi

\begin{tabular}{lllll}
\hline Group & Day 0 & Day 6 & Day 11 & Day 16 \\
\hline Control & $6.47 \pm 0.72$ & $6.47 \pm 0.72$ & $6.47 \pm 0.72$ & $6.47 \pm 0.72$ \\
Neg. Control & $16.20 \pm 1.79 * *$ & $16.80 \pm 1.29 * *$ & $17.47 \pm 1.35 * *$ & $18.13 \pm 1.28 * *$ \\
Low Dose & $16.20 \pm 1.79 *$ & $13.03 \pm 1.45$ & $* 10.60 \pm 1.72^{* * *}$ & $8.67 \pm 0.49 * * *$ \\
Medium Dose & $16.20 \pm 1.79 *$ & $11.60 \pm 1.21$ & $9.67 \pm 0.61 * * *$ & $6.90 \pm 0.58^{* * * *}$ \\
High Dose & $16.20 \pm 1.79 *$ & $10.67 \pm 0.64$ & $8.57 \pm 0.88^{* * *}$ & $5.83 \pm 0.56^{* * * *}$ \\
Ciprofloxacin & $16.20 \pm 1.79 *$ & $11.27 \pm 1.32$ & $9.13 \pm 1.08^{* * *}$ & $6.83 \pm 0.84 * * *$ \\
\hline
\end{tabular}

\section{Histological Plates of the Liver}

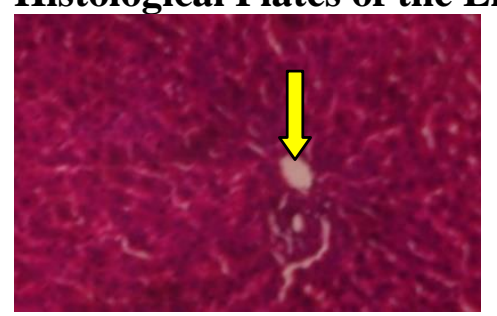

Plate 1: Photomicrograph of liver tissues of normal rats showing normal histoarchitecture with the central vein and hepatic plates of the liver were radially placed. The sinusoids are well dilated and some Kupfer cells were seen in the sinusoidal place (Normal-Day 6). 




Plate 2: Photomicrograph of liver tissues of $S$. typhi infected rats showing necrosis (negative control-Day 6).

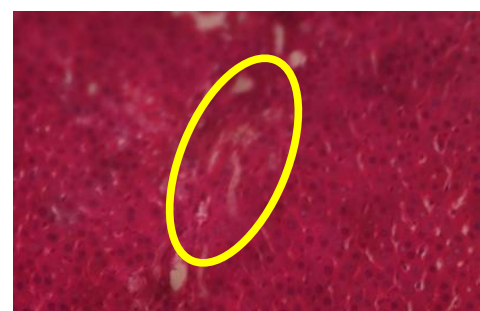

Plate 3: Photomicrograph of liver tissues of rat infected with s. typhi and treated with $500 \mathrm{mg}$ of ciprofloxacin for 5 days showing no tissue disruption. At the center of the field is the portal triad which is usually the intensity of the branches of the hepatic artery vein and portal vein. The sinusoids were also well dilated and no inflammatory cells were seen.

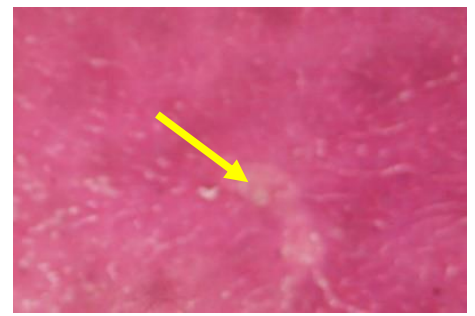

Plate 4: Photomicrograph of liver tissues of rat infected with $S$. typhi and treated with $100 \mathrm{mg}$ of $C$. odorata for 5 days showing destroyed hepatic tissues architecture.

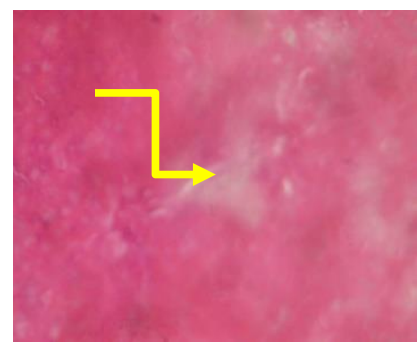

Plate 5: Photomicrograph of liver tissues of rat infected with S. typhi and treated with $200 \mathrm{mg}$ of $C$. odorata for 5 days. There is congestion of the sinusoids and fuzzy appearance of the hepatic plates. 


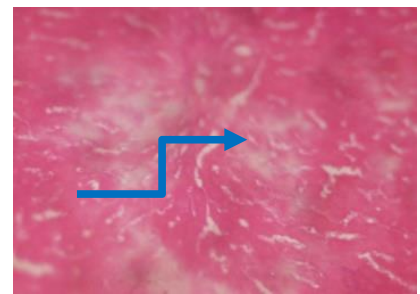

Plate 6: Photomicrograph of liver tissues of rat infected with S. typhi and treated with $400 \mathrm{mg}$ of $C$. odorata for 5 days showing destroyed hepatic tissue architecture with highly dilated sinusoids.

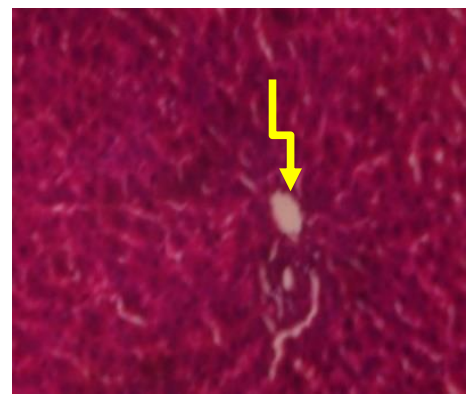

Plate 7: Photomicrograph of liver tissues of normal rats showing normal histoarchitecture with the central vein and hepatic plates of the liver which were radially placed. The sinusoids are well dilated and some Kupfer cells were seen in the sinusoidal place (Normal-Day 11).

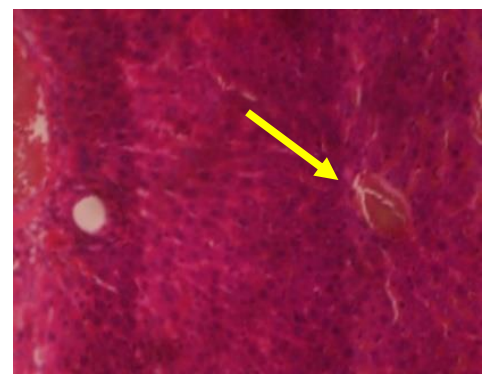

Plate 8: Photomicrograph of liver tissues of S. typhi infected rats showing necrosis (negative control-Day 11).

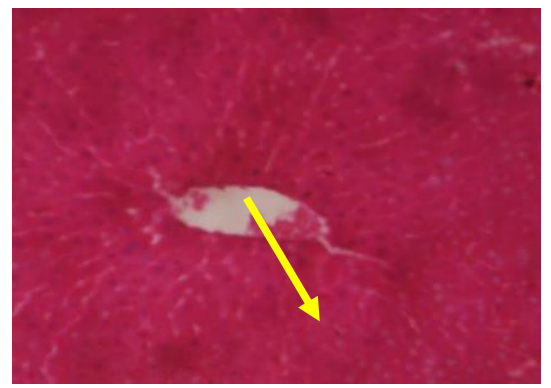

Plate 9: Photomicrograph of liver tissues of rat infected with S. typhi and treated with $500 \mathrm{mg}$ of ciprofloxacin for 10 days. The hepatic tissue had 
sinusoids with well defined hepatic plates. There was no presence of inflammatory cells.

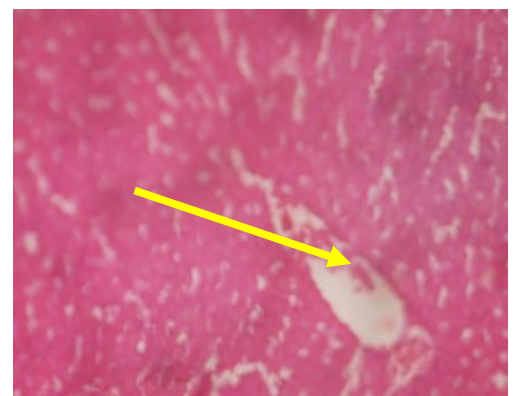

Plate 10: Photomicrograph of liver tissues of rat infected with S. typhi and treated with $100 \mathrm{mg}$ of $C$. odorata for 10 days showing slight tissue disruption.

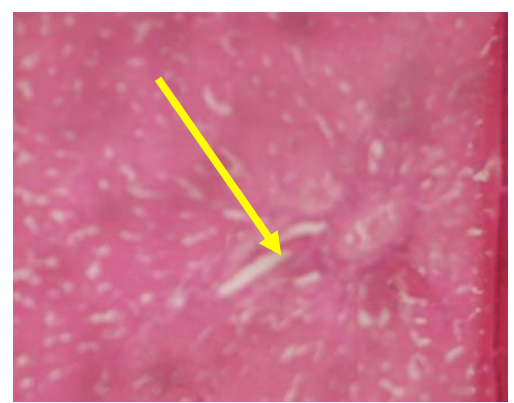

Plate 11: Photomicrograph of liver tissues of rat infected with S. typhi and treated with $200 \mathrm{mg}$ of $C$. odorata for 10 days with clearly defined hepatic plates and sinusoids.

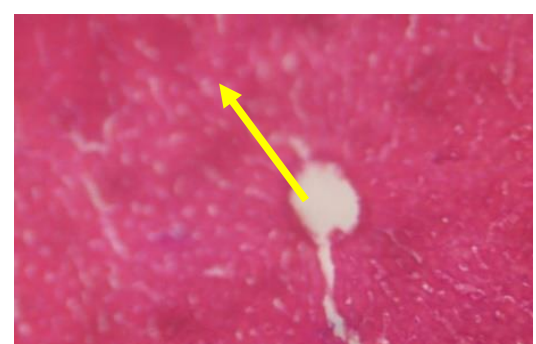

Plate 12: Photomicrograph of liver tissues of rat infected with S. typhi and treated with $400 \mathrm{mg} / \mathrm{kg}$ of $C$. odorata for 10 days. The sinusoids are still fairly dilated. The hepatic plates are in radial disposition towards the central vein. 


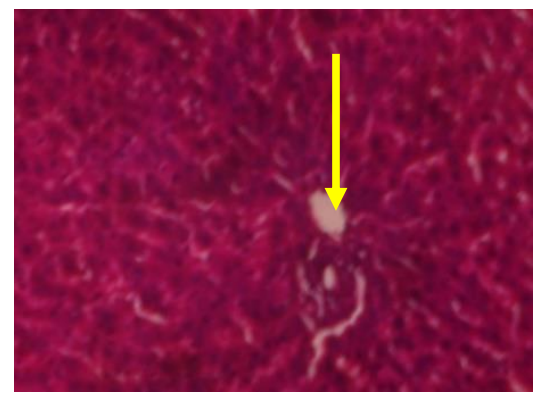

Plate 13: Photomicrograph of liver tissues of normal rats showing normal histo-architecture with the central vein and hepatic plates of the liver were radially placed. The sinusoids are well dilated and some Kupfer cells were seen in the sinusoidal place (Normal-Day 16).

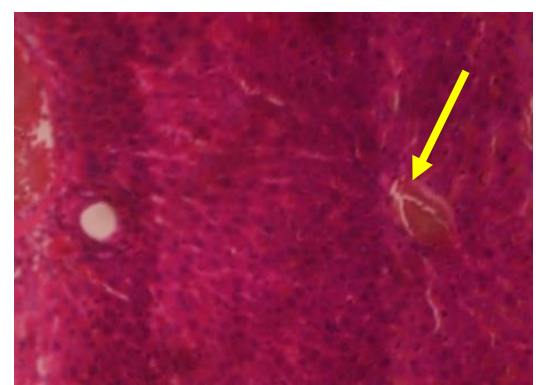

Plate 14: Photomicrograph of liver tissues of S. typhi infected rats showing necrosis (negative control-Day 16).

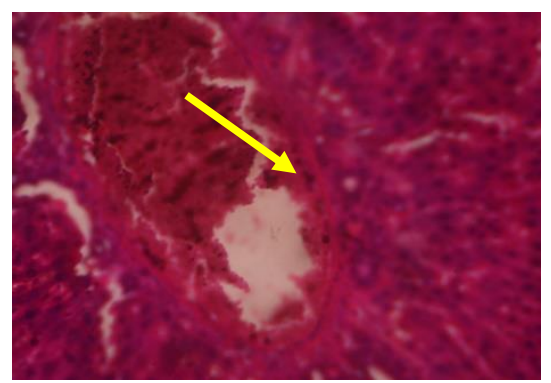

Plate 15: Photomicrograph of liver tissues of rat infected with $S$. typhi and treated with $500 \mathrm{mg}$ of ciprofloxacin for 15 days. The liver tissue showed the interlobular region with congested interlobe portal vein. The hepatocytes had normal architecture. 


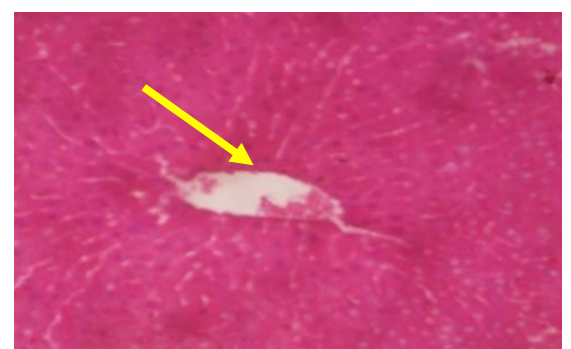

Plate 16: Photomicrograph of liver tissues of rat infected with $S$. typhi and treated with $100 \mathrm{mg}$ of $C$. odorata for 15 days. Picture shows normal hepatic tissue.

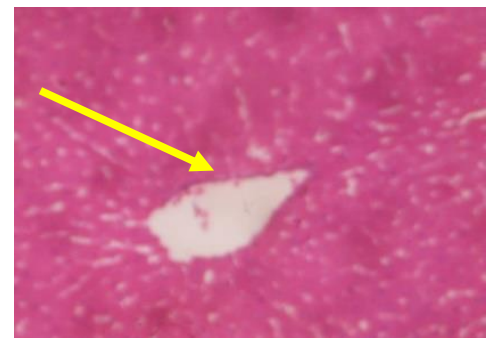

Plate 17: Photomicrograph of liver tissues of rat infected with $S$. typhi and treated with $200 \mathrm{mg}$ of $C$. odorata for 15 days, showing normal tissue architecture revealing a central vein and radially placed hepatic plates clearly demarcated by sinusoids.

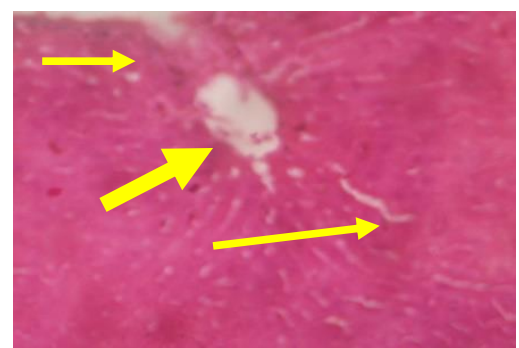

Plate 18: Photomicrograph of liver tissues of rat infected with S. typhi and treated with $400 \mathrm{mg} / \mathrm{kg}$ of $C$. odorata for 15 days showing normal tissues. The hepatic plates are in radial disposition towards the central vein.

\section{Discussion}

An increased liver enzyme activity is the basis, according to Mohd et al. (2013), for which liver disease is often first suspected, as they reported that an injury to the hepatic cells causes a distortion of metabolic function. They also remarked that it is the liver test that reveals the integrity of the hepatocyte membrane, necrosis of hepatocytes or biliary epithelia, cholestasis or induction phenomenon. In the presence of liver disease, the hepatocyte membrane becomes more permeable and some of the enzymes leak out into 
the blood circulation, thus resulting in moderate elevations of transaminases in the blood (Nwachukwu, et al., 2015). In this study, it was observed that inoculation of Wistar rats with Salmonella typhi caused an increase in the levels of aspartate aminotransferase (AST), alanine aminotransferase (ALT), alkaline phosphatase (ALP), total bilirubin (TB), albumin and total protein (TP), and an insignificant increase in Conjugated Billirubin (CB). These changes may have occurred due to hepatic damage resulting from local or systemic adverse effects of particular endotoxin, non-specific inflammatory reactions in response to cytotoxins generated and released by Salmonella typhi that have infected Kuffer cells (Sallie et al., 1991; Adeyi et al., 2013; Damilola et al., 2015). It was also observed that administration of MLECO reversed the adverse hepatotoxicological changes, in keeping with previous reports by Jude et al. (2014), who reported a reduction in liver and kidney markers including aspartate aminotransferase (AST) and alanine aminotransferase (ALT) on administration of Chromolaena odorata leaf extract to Wistar rats. These effects could be attributed to the anti-bacterial effects of Chromolaena odorata on the Kuffer cells (Lovet \& Douye, 2013). Treatment of infected animals with the different doses of the extract has caused a restoration to normal liver histo-architecture by day 16, indicating that even the low dose was effective at reversing these pathological changes in the liver.

\section{Conclusion}

MLECO reversed the adverse hepatotoxicological and pathological changes in the liver induced by $S$. tyhi infection in a dose-dependent manner, with the $200 \mathrm{mg}$ and $400 \mathrm{mg}$ doses being more effective at reversing liver changes than ciprofloxacin.

\section{References:}

1. Abro, A. H., Abdou, A. M., Gangwani, J. L., Ustadi, A. M., Younis, N. J., \& Hussaini, H. S. (2009). Hematological and biochemical changes in typhoid fever. Pak J Med Sci., 25 (2), 166-171.

2. Adeyi, A. O., Jinadu, A. M., Arojojoye, O. A., Alao, O. O., Ighodaro, O. M., \& Adeyi, O. E. (2013). In vivo and in vitro antibacterial activities of Momordica charantia on Salmonella typhi and its effect on liver function in typhoid-infected rats. Journal of Pharmacognosy and Phytotherapy, 5(11), 183-188.

3. Asomugha, R. N., Okafor, P. N., Ijeh, I., Orisakwe, O. E., Asomugha, A. L. (2014). Hepatic effects of aqueous extract of Chromolaena odorata in male Wistar albino rats, Pharmacology online Achive, 1, 127-136.

4. Babson, L. A., Greeley, S. J., Coleman, C. M., \& Philips, G. D. (1966). Clin. Chem., 12, 482-490. 
5. Baker, J. R. (1945). Cytological Technique. (2nd ed.), (p. 211). London: Methuen.

6. Damilola, A. O., Garba, J. D., Wilson, I. E. \& Ume, U. A. (2015). Anti-typhoid and hepatic response in Salmonella typhi infected rats treatedwith ethanol leaf extract of Tithonia diversifolia. Asian Journal of Plant Science and Research. 5(8), 34-46.

7. Doumas, B. T., Watson, W. A., \& Biggs, H. G., (1971). Clin. Chim. Acta, 31, 87.

8. Grant, G. H. (1987). Amino Acids and Proteins; Fundamentals of Clinical Chemistry, Tietz, N. W. Editor, $3^{\text {rd }}$ Edition. WB Saunders Company Philadelphia USA, 328-329.

9. Haque, S. S., Sharan, A., \& Kumar U. (2011). Histopathological examination of formulated drugs against typhoid. Research In Pharmaceutical Biotechnology, 3(10), 135-141.

10. Hanan, B., Akram, H., Hassan, R., Ali, H., Zeinab, S., \& Bassam, B. (2013). Techniques for the Extraction of Bioactive Compounds from Lebanese Urtica dioica. Maceration method. American Journal of Phytomedicine and Clinical Therapeutics, 1(6), 507-513

11. Haque, S. S., Sharan, A., \& Kumar U. (2011). Histopathological examination of formulated drugs against typhoid. Research In Pharmaceutical Biotechnology, 3(10), 135-141.

12. Jude, C. I., Catherine, C. I., \& Mercy, O. I. (2014). Aqueous Extract of the Leaves of Chromolaena odorata Moderated Plasma Biochemical and Hematological Indices of Sub-Chronic Salt-Loaded Rats. Asian J. Pharm. Res, 4 (1), 24-35.

13. Klein, B., Read, P. A. \& Babson, L. A. (1960). Clin. Chem., 6, 269275.

14. Lovet, T. K., \& Douye, V. Z. (2013). Activity of Chromolaena odorata on enteric and superficial etiologic bacterial agents. American Journal of Research Communication. 1(11): 266-278.

15. Mirsadraee, M., Shirdel, A., \& Roknee, F. (2007). Typhoid Myopathy or typhoid hepatitis: A matter of debate. Ind J Med Microb; 25:351-3.

16. Mohd Azam Hyder, Marghoob Hassan and abdelmarouf Hassan Mohieldein (2013). Comparative Level of ALT, AST, ALP and GGT in liver associated disease. European Journal of Experimental Biology, 3(2), 280-284

17. Momoh, A. O., Adebolu, T. T., \& Ogundare, A. O. (2013). Evaluation of beniseed extract and fermented liquors in treatment of diarrhoea in albino rats infected with Salmonella typhi. European Journal of Biology and Medical Science Research 1 (2), 16-23.

18. Morgenstern, R., \& Hayes, P. C. (1991). The liver in typhoid: Always affected, not just a complication. Am J Gastroentrol, 86, 12335-12339. 
19. Musa, T. Y. (2012). Effect of a 60-Day Oral Gavage of a Crude Alkaloid Extract From Chromolaena odorata Leaves on Hormonal and Spermatogenic Indices of Male Rats, Journal of Andrology, 33 (6), 1199-1207.

20. Nwachukwu, F. C., Odo, C. E., Ihegboro, G. O (2015). Effects of Repeated Administration of Chromolaena odorata on selected liver function parameters of apparently healthy Wistar Rats, European Journal of Biology and Medical Science Research, 3 (2), 13-24.

21. Ogbonnia, S. O., Mbaka, G. O., Anyika, E. N., Osegbo, O. M., \& Igbokwe, N. H. (2010). Evaluation of acute toxicity in mice and subchronic toxicity of hydroethanolic extract of Chromolaena odorata (L.) King and Robinson (Fam. Asteraceae) in rats, Agric. Biol. J. N. Am., 1(5), 859-865.

22. Reitman, S., \& Frankel, S. (1957). A colorimetric method for the determination of serum glutamic oxalacetic and glutamic pyruvic transaminases. Amer. J. Clin. Patho, 28, 56-63.

23. Sallie, R., Tredger, R. S., Williams, R. (1991). Drugs and the Liver. Biopharmaceutical Drug Dispos, 12, 251.259

24. Schmidt, E., \& Schmidt, F. W. (1963). Enzym. Biol. Clin, 3, .

25. Tietz, N. W. (1995). Clinical Guide to Laboratory Tests. ( $3^{\text {rd }}$ Edition), WB Saunders Company Philadelphia P.A pp 518-519. 